\title{
Heavy Metal Tolerance and Antibiotic Resistance of Bacillus spp. Isolated from Two Major Rivers in Bangladesh
}

\author{
Tahmina Shammi ${ }^{1}$ and Sangita Ahmed ${ }^{1 *}$ \\ ${ }^{1}$ Department of Microbiology, University of Dhaka, Dhaka-1000, Bangladesh
}

\begin{abstract}
Pollution of the environment with toxic heavy metals is spreading throughout the world along with industrial progress. Removal of these toxic heavy metals by using bacteria has achieved growing attention in recent years. The present study focuses on isolation of lead and chromium tolerant Bacillus spp., from the Buriganga and the Shitalkhya, the two major rivers surrounding Dhaka. A total of 25 Bacillus spp. isolates tolerant to 50 ppm lead and chromium were preliminarily identified based on morphological and biochemical analysis. Further investigation revealed that all isolates were also able to grow at $1000 \mathrm{ppm}$ lead and $400 \mathrm{ppm}$ chromium, while tolerance to $1500 \mathrm{ppm}$ lead and $500 \mathrm{ppm}$ chromium was observed among $48 \%$ and $76 \%$ isolates, respectively. All isolates were also able to grow at $50 \mathrm{ppm}$ copper and $50 \mathrm{ppm}$ zinc, while $72 \%$ grew at $100 \mathrm{ppm}$ copper. The heavy metal tolerant Bacillus spp were also multi drug resistant and showed resistance to Tetracycline (100\%), Ceftazidime (100\%), Ceftriaxone (100\%), Ampicillin (28\%) and Nalidixic acid (24\%).
\end{abstract}

Key words: Bacillus, heavy metal, antibiotic

\section{Introduction}

Water pollution in Dhaka city, Bangladesh has been a serious problem for years and increasing urbanisation is worsening the situation. Water supply in Dhaka mainly depends on the rivers Buriganga, Turag, Shitalakhya and Balu, which in recent years have been polluted to such an extent that it is getting very difficult to cope up with the increasing demand of usable water. The pollution is both biological and chemical, resulting from sewerage lines dumplings and toxic wastes originating from different types of industries ${ }^{1}$. In 2010, analysis of the heavy metal content of water in the Buriganga showed that concentrations of lead $(\mathrm{Pb})$, Cadmium (Cd), Nickel (Ni), (Copper) Cu and Chromium (Cr) range from 58.17 to $72.45 \mu \mathrm{g} / \mathrm{L}, 7.08$ to $12.33 \mu \mathrm{g} / \mathrm{L}, 7.15$ to $10.32 \mu \mathrm{g} / \mathrm{L}$, 107.38 to $201.29 \mu \mathrm{g} / \mathrm{L}$ and 489.27 to $645.26 \mu \mathrm{g} / \mathrm{L}$, respectively ${ }^{2}$. For most of these heavy metals this concentration exceed the acceptable level set by the Environmental Quality Standards (1997), Department of Environment, Government of the Peoples' Republic of Bangladesh ${ }^{3}$ which is $50 \mu \mathrm{g} / \mathrm{L}$ for lead, $5 \mathrm{mg} / \mathrm{L}$ for cadmium, $1000 \mathrm{mg} / \mathrm{L}$ for copper, $100 \mu \mathrm{g} / \mathrm{L}$ for nickel and $50 \mathrm{mg} / \mathrm{L}$ for chromium and impose great risk to public health. Most of these heavy metals are toxic and carcinogenic for human and may lead to death in extreme cases. Among these, lead and hexavalent chromium are of particular concern due to their major impact on human and other forms of lives ${ }^{4}$. In children, exposure to high concentration of lead and chromium can cause potentially permanent learning and behavior disorders. These metals are also toxic for adults, having deleterious effects on heart, bones, intestines, kidneys, reproductive and nervous systems and leading to death in extreme cases ${ }^{4}$. Therefore, to ensure good public health, it is very important to remove these heavy metals from aquatic bodies in Bangladesh.
There are limited strategies for removal of heavy metals from environment, most of which are physicochemical methods and possess several disadvantages, such as less affectivity, high costs, generation of toxic sludges as well as the problem of the safe disposal of the materials ${ }^{5}$. As an alternative to the physicochemical removal methods, use of microorganism to reduce, eliminate or detoxify heavy metals has achieved growing attention in recent years ${ }^{5-9}$. Additionally in several investigations, bacterial species have been isolated from several aquatic systems which were tolerant to different types of heavy metals and were also resistant to a variety of antibiotics, indicating to a strong correlation between metal resistance and antibiotic resistance among microbes ${ }^{10-13}$. In a number of studies aerobic, gram positive, endospore forming multi-drug resistant Bacillus spp has been found to be associated with the bioremediation of heavy metals $6,7,10,13-14$. It is possible that these bacteria utilize similar mechanisms to survive under metal and antibiotic stressed condition. Therefore, to understand the mechanism of heavy metal bioremediation by Bacillus spp, it is necessary to study the antibiotic resistance as well. This study therefore specifically focuses to isolate Bacillus spp with tolerance to increased concentration of lead and chromium from polluted water of the rivers Buriganga and Shitalkhya aiming to find out a solution to remove these pollutants from the river water.

\section{Materials and Methods}

\section{Sampling sites}

The aim of this study is to isolate Bacillus spp with bioremediation capacity of heavy metals lead and Chromium. Therefore, aquatic environments heavily contaminated with industrial pollutant, especially pollutant from textile and tannery that would be enriched 
with these heavy metals was selected as sampling sites. Three samples were collected for this study from the following three sites.

Sample 1: Pagla, Buriganga (2340’0"N; 90²7’0"E)

Sample 2: Kamrangirchar, Buriganga $\left(23.715278^{\circ} \mathrm{N} 90.373611^{\circ} \mathrm{E}\right)$

Sample 3: The River Sitalakshya, (2343’18.48"N; 90³0’1.8"E)

\section{Sample collection and transportation}

Sterile capped Schott Duran bottle was used to collect sample aseptically. Water samples were drawn from 63 to 13 below the surface water by wearing sterile gloves. After collection, the container was capped properly. Three samples were collected from each sites and transported to laboratory in insulated box as soon as possible.

\section{Isolation of heterotrophic metal tolerant bacteria}

To isolate lead and chromium resistant bacteria $10 \mathrm{ml}$ water sample was inoculated into Luria-Bertani agar medium, each supplemented with 50ppm lead and chromium, by spread plate method ${ }^{5,7}$. The plates were incubated at $37^{\circ} \mathrm{C}$ for 24 hours. Following incubation, growth of the isolates were observed very carefully. The morphologically dissimilar isolated colonies were picked up from the plates and subcultured on LB agar to obtain pure colonies.

\section{Identification of the Bacillus species}

To identify lead and chromium tolerant Bacillus spp, all isolates were screened for their Gram reaction by Gram staining method. Isolates which appeared as Gram positive, large rod shaped organisms were further screened for their colony morphology and biochemical tests (catalase test, oxidase test, motility assay, carbohydrate fermentation test, gelatin hydrolysis, starch hydrolysis and endospore staining) as suggested by the Bergey's Manual of Bacteriology ${ }^{15}$.

\section{Analysis of heavy metal tolerance pattern by MTCs (Maximum Tolerance Concentration)}

To determine the maximum tolerance concentration of lead and chromium of the presumptive Bacillus isolates, each isolate was grown at $37^{\circ} \mathrm{C}$ for 48 hours in $5 \mathrm{ml}$ Luria-Bertani (LB) broth medium in screw capped tubes supplemented with different concentrations of each metal. Stock solutions of lead as $0.5 \mathrm{M}$ $\mathrm{Pb}\left(\mathrm{NO}_{3}\right)_{2}$ and chromium as $4.0 \mathrm{M} \mathrm{K}_{2} \mathrm{Cr}_{2} \mathrm{O}_{7}$ were prepared and filter sterilized. From each stock solution, appropriate amount was added in LB to dissolve lead in the concentration ranging from 500 to $1500 \mathrm{ppm}$ and chromium ranging from 200 to 1500 ppm). Analysis of resistance to copper and zinc was also determined in a similar way. Copper was added to $\mathrm{LB}$ medium as $\mathrm{CuSO}_{4} \cdot 5 \mathrm{H}_{2} \mathrm{O}$ (50 and $100 \mathrm{ppm}$ ) and zinc was added as $\mathrm{ZnSO}_{4} . \mathrm{H}_{2} \mathrm{O}$ (50 ppm).

Following incubation at $37^{\circ} \mathrm{C}$ for 48 hours, each bacterial culture (10 ml) was spread over Luria-Bertani agar plates in duplicate and incubated at $37^{\circ} \mathrm{C}$ for $24-72$ hours to test any appearance of growth. The presence or absence of growth was determined visually as positive or negative. The absence of bacterial growth indicated its sensitivity to that particular concentration of heavy metal, while the presence of growth at certain heavy metal concentration indicated that the bacterial isolates was tolerant to that concentration.

\section{Analysis of antibiotic resistance pattern}

Bacterial susceptibility to anti-microbial agent was determined in vitro by standardized agar-disc diffusion method known as the Kirby Bauer method ${ }^{16}$ using commercial antibiotic discs (Oxoid, UK). Antibiotics and disc potencies used were Ampicillin (AMP 10), Tetracycline $10 \mu \mathrm{g}$ (TET 10), Ceftazidime $30 \mu \mathrm{g}$ (CAZ 30), Ceftriaxone $30 \mu \mathrm{g}$ (CRO 30), Gentamicin $10 \mu \mathrm{g}$ (CN 10), Nalidixic Acid $30 \mu g$ (NA 30), Imipenem $10 \mu g$ (IPM 10) and Ciprofloxacin 5 $\mu g$ (CIP 5).

A suspension of each test organism was prepared and was diluted with normal saline to match the equivalent turbidity of 0.5 MacFarland standards. A sterile cotton swab was dipped into suspension and excess fluid was removed by pushing and rotating the swab firmly against the inside of the tube above the fluid level. The swab was then streaked evenly over the entire surface of a Muller-Hinton Agar (pH 7.3) plate to obtain uniform inoculum. Antibiotic discs were then applied aseptically to the surface of the inoculated plates with appropriate spatial arrangement by means of sterile forceps. The plates were then inverted and incubated at $37^{\circ} \mathrm{C}$ for 24 hours. After incubation, the plates were examined and the diameters of the zones of complete inhibition were measured in millimeter. The zone diameter for individual anti-microbial and agents were translated into susceptible, intermediate and resistant categories by referring to an interpreting table ${ }^{16}$.

\section{Results}

Isolation of heavy metal tolerant Bacillus spp

Initial screening of the water samples on Laurea-Bertani agar medium, supplemented with 50ppm lead and chromium resulted in isolation of 61 distinct colonies. Each colony was subcultured on Laurea-Bertani medium and was screened for colony morphology and Gram reaction by Gram staining method. Among 61 isoltes 25 (41\%) appered as gram positive large rod which was charactersitic of Bacillus spp. These isolates were carried over for further chracterisation.

Identification of the Bacillus spp by Biochemical characterization The bacterial isolates which were found to be Gram positive rod were further identified using several biochemical tests as summarized in Table 1. As a positive control, a standard strain of Bacillus cereus was used. Majority of the isolates showed similar results, typical of Bacillus spp in all biochemical tests ${ }^{15}$. The exceptions were isolate 24 which showed negative results in oxidase test and starch hydrolysis test and isolates 39, 47, 52 and 55 which did not hydrolyze starch. 
Table 1. Identification of the isolates based on biochemical characteristics

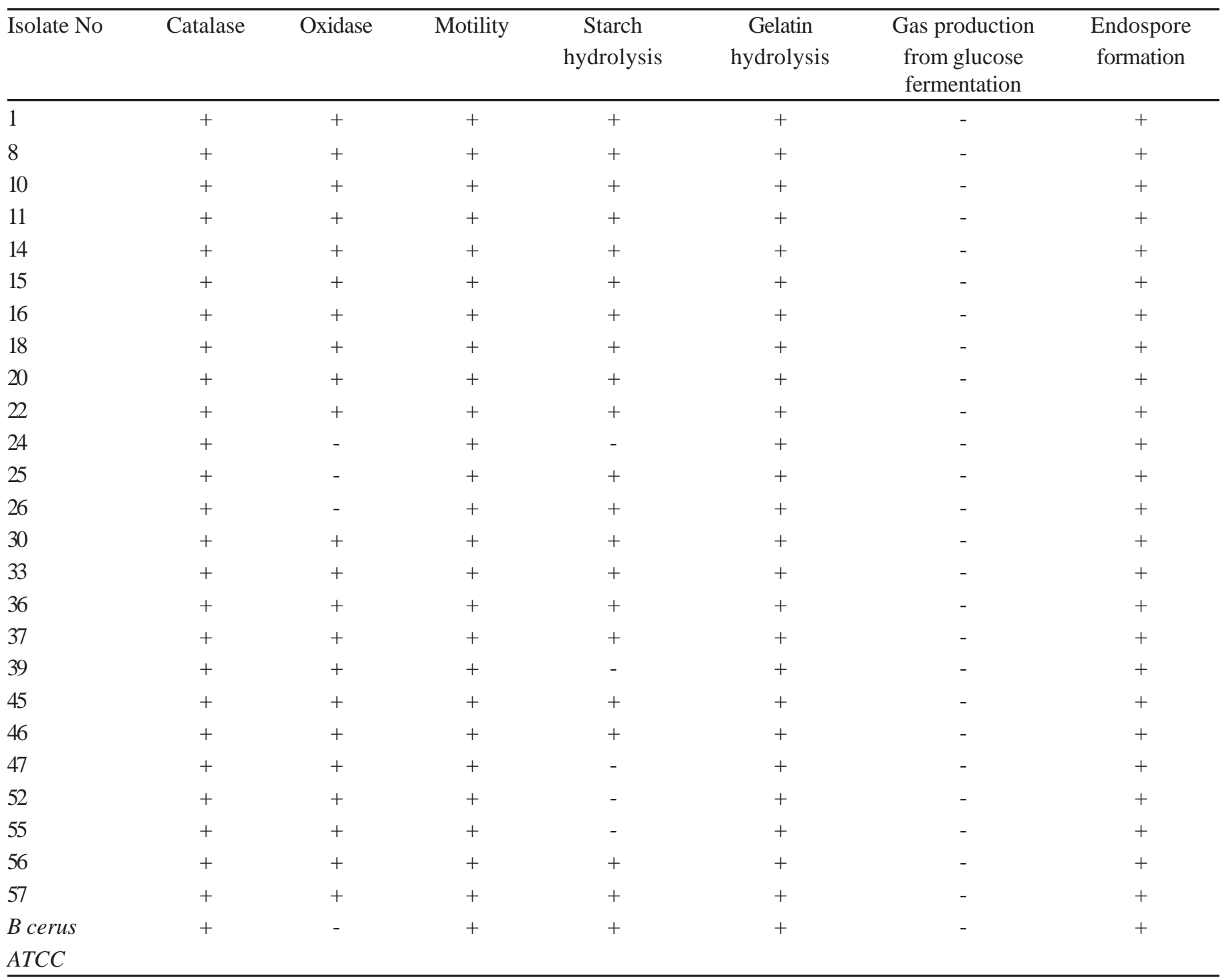

Determination of Maximum Tolerance Concentration (MTC) against heavy metals

Maximum Tolerance Concentration (MTC) against lead

All the presumptive Bacillus spp isolates were tested for their tolerance to different concentrations of lead. The results showed that all isolates could tolerate 1000 ppm lead while, 48\% were tolerant to 1500 ppm lead (Figure 1).

Maximum Tolerance Concentration (MTC) against chromium

All the presumptive Bacillus spp isolates were tested for their tolerance to different concentrations of chromium. The results showed that among all 25 isolates could tolerate $400 \mathrm{ppm}$ chromium and 19 of them (76\%) could tolerate 500 ppm chromium (Figure 1).

Maximum Tolerance Concentration (MTC) against copper and zinc

To investigate whether lead and chromium tolerant Bacillus spp possess tolerance to other heavy metals they were further tested for their tolerance to different concentrations of copper and Zinc. It was observed that all isolates were tolerant to $50 \mathrm{ppm}$ Zinc and failed to grow above this concentration. About 18 (72\%) isolates could tolerate 100 ppm copper while 7 isolates (28\%) failed to grow at this concentration and could tolerate only 50 ppm (Figure 2).

Antibiotic resistance pattern of the heavy metal tolerant Bacillus isolates

The exposure of microorganism to heavy metals results in the selection of bacterial strains which are also able to resist antibiotics $^{10-13}$. Therefore the heavy metal tolerant Bacillus spp were tested for their sensitivity to different antibiotics. It was observed that all the 25 isolates were resistant to three antibioticsTetracycline, Ceftazidime and Ceftriaxone, while all were sensitive to Imipenem (Table 2). Among other antibiotics tested, 28\% and 24\% isolates showed resistance to Ampicillin and Nalidixic acid, respectively. Only 4\% isolates were found to be resistant to Gentamicin. These observations suggest that the heavy metal tolerant Bacillus isolates are also multi-drug resistant. 


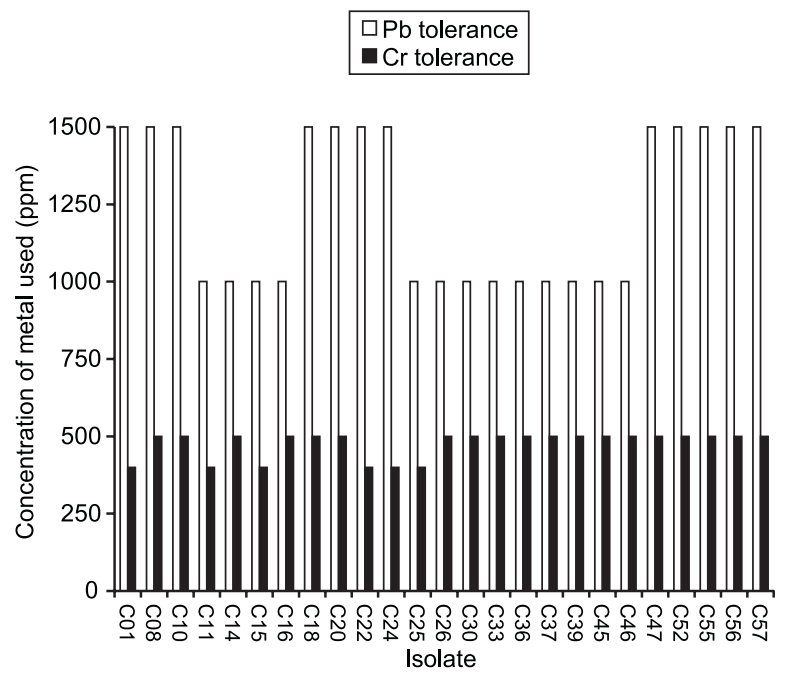

Figure 1. Maximum tolerance concentration (MTC) of Bacillus isolates against lead and chromium.

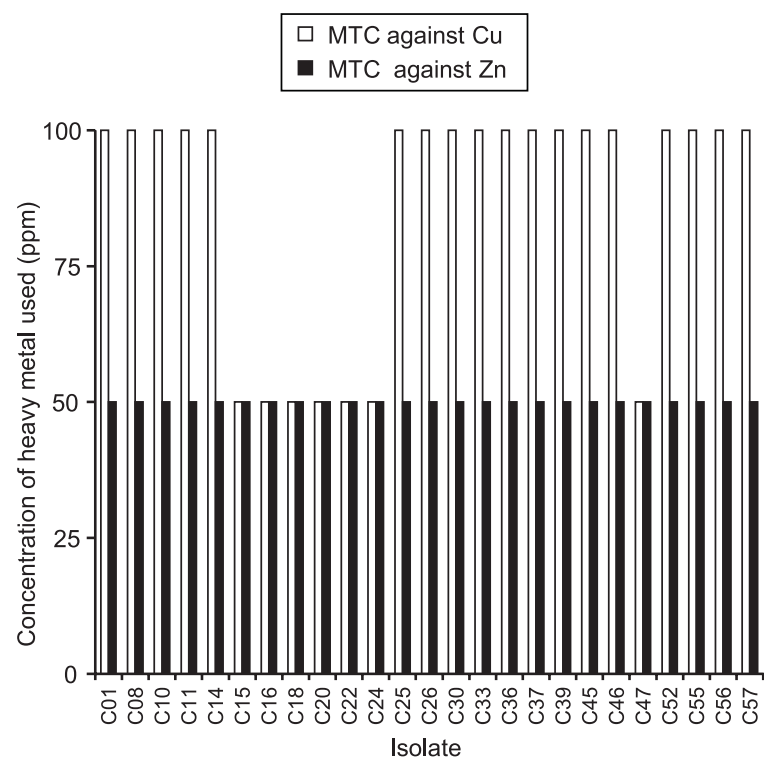

Figure 2. Maximum tolerance concentration (MTC) of Bacillus isolates against copper and zinc

Table 2. Antibiotic sensitivity profile of the Bacillus spp. isolates

\begin{tabular}{|c|c|c|c|c|c|c|c|c|}
\hline Isolates & $\begin{array}{l}\text { Ampicillin } \\
\text { (AMP) }\end{array}$ & $\begin{array}{c}\text { Imipenem } \\
\text { (IPM) }\end{array}$ & $\begin{array}{l}\text { Tetracycline } \\
\text { (TE) }\end{array}$ & $\begin{array}{c}\text { Ceftazidime } \\
\text { (CAZ) }\end{array}$ & $\begin{array}{l}\text { Ciprofloxacin } \\
\text { (CIP) }\end{array}$ & $\begin{array}{c}\text { Nalidixic } \\
\text { acid (NA) }\end{array}$ & $\begin{array}{c}\text { Ceftriaxone } \\
\text { (CRO) }\end{array}$ & $\begin{array}{c}\text { Gentamicin } \\
(\mathrm{CN})\end{array}$ \\
\hline $\mathrm{C} 1$ & $\mathrm{R}$ & $S$ & $\mathrm{R}$ & $\mathrm{R}$ & $S$ & I & $\mathrm{R}$ & $S$ \\
\hline $\mathrm{C} 8$ & $\mathrm{R}$ & S & $\mathrm{R}$ & $\mathrm{R}$ & I & I & $\mathrm{R}$ & S \\
\hline $\mathrm{C} 10$ & $\mathrm{R}$ & S & $\mathrm{R}$ & $\mathrm{R}$ & S & $\mathrm{R}$ & $\mathrm{R}$ & S \\
\hline C14 & S & S & $\mathrm{R}$ & $\mathrm{R}$ & S & $\mathrm{R}$ & $\mathrm{R}$ & S \\
\hline C15 & I & S & $\mathrm{R}$ & $\mathrm{R}$ & S & I & $\mathrm{R}$ & S \\
\hline C16 & I & S & $\mathrm{R}$ & $\mathrm{R}$ & S & I & $\mathrm{R}$ & S \\
\hline C18 & I & S & $\mathrm{R}$ & $\mathrm{R}$ & I & I & $\mathrm{R}$ & S \\
\hline C19 & $\mathrm{R}$ & S & $\mathrm{R}$ & $\mathrm{R}$ & S & I & $\mathrm{R}$ & S \\
\hline C20 & $\mathrm{R}$ & S & $\mathrm{R}$ & $\mathrm{R}$ & S & S & & S \\
\hline $\mathrm{C} 22$ & I & S & $\mathrm{R}$ & $\mathrm{R}$ & S & $\mathrm{R}$ & $\mathrm{R}$ & S \\
\hline C24 & S & S & $\mathrm{R}$ & $\mathrm{R}$ & S & I & $\mathrm{R}$ & S \\
\hline $\mathrm{C} 25$ & I & S & $\mathrm{R}$ & $\mathrm{R}$ & S & I & $\mathrm{R}$ & S \\
\hline C26 & I & S & & $\mathrm{R}$ & S & $\mathrm{R}$ & $\mathrm{R}$ & \\
\hline С 30 & S & S & $\mathrm{R}$ & $\mathrm{R}$ & S & $\mathrm{R}$ & $\mathrm{R}$ & S \\
\hline C33 & I & S & $\mathrm{R}$ & $\mathrm{R}$ & S & S & $\mathrm{R}$ & $\mathrm{R}$ \\
\hline C36 & $\mathrm{R}$ & S & $\mathrm{R}$ & $\mathrm{R}$ & S & I & & $S$ \\
\hline C37 & I & S & $\mathrm{R}$ & $\mathrm{R}$ & S & I & $\mathrm{R}$ & S \\
\hline C39 & S & S & $\mathrm{R}$ & $\mathrm{R}$ & S & S & $\mathrm{R}$ & S \\
\hline C45 & $\mathrm{R}$ & S & $\mathrm{R}$ & $\mathrm{R}$ & S & I & $\mathrm{R}$ & S \\
\hline C46 & $S$ & S & $\mathrm{R}$ & $\mathrm{R}$ & S & I & $\mathrm{R}$ & I \\
\hline CA7 & $S$ & $S$ & $\mathrm{R}$ & $\mathrm{R}$ & S & I & $\mathrm{R}$ & $S$ \\
\hline C52 & S & S & $\mathrm{R}$ & $\mathrm{R}$ & S & $\mathrm{R}$ & $\mathrm{R}$ & S \\
\hline C55 & S & $S$ & $\mathrm{R}$ & $\mathrm{R}$ & S & S & $\mathrm{R}$ & S \\
\hline C56 & S & S & $\mathrm{R}$ & $\mathrm{R}$ & S & S & $\mathrm{R}$ & S \\
\hline C57 & S & S & $\mathrm{R}$ & $\mathrm{R}$ & S & S & $\mathrm{R}$ & S \\
\hline
\end{tabular}




\section{Discussion}

Metal resistance and heavy metal bioremediation potential of chemoorganotrophic bacteria like Bacillus are well known ${ }^{6,8-10}$. Microbe related technologies may provide an alternative or addition to conventional method of metal removal or metal recovery. This study was therefore aimed to isolate Bacillus spp with bioremediation potential of heavy metals lead and chromium from heavy metal polluted river waters, which could be used as a cheap and eco-friendly alternative for metal bioremediation.

In this study some basic biochemical tests which are unique for Bacillus spp. were selected to identify the Gram positive rods. These include oxidase, catalase, endospore formation, motility, starch hydrolysis, gelatin hydrolysis and gas production from carbohydrates. All isolates showed similar characteristics in all experiments, except in oxidase and starch hydrolysis experiments where some variations were observed. However, Bacillus is a Bacillus is one of the largest bacterial genera and members of this genus show varied results for single biochemical test. Further identification of these isolates by 16S rRNA gene sequencing would allow accurate identification at species level.

Of the 25 Bacillus isolates, $48 \%$ could tolerate $1500 \mathrm{ppm}$ of lead, while $76 \%$ were able to grow at $500 \mathrm{ppm}$ chromium. All were able to grow in $50 \mathrm{ppm}$ Copper and Zinc, while 18 isolates (72\%) could tolerate 100 ppm Copper. Similarly isolation of Bacillus spp tolerant to a range of heavy metals like chromium, cadmium, nickel and cobalt have been reported by Samanta et al. ${ }^{10}$. Bahig et al. ${ }^{17}$ also isolated Bacillus spp. from agricultural soil in Egypt which were tolerant to multiple metals such as lead, chromium, mercury, cadmium, cobalt, nickel and arsenic. Among the 25 Bacillus isolates obtained in current study, 6 (isolate no C08, C10, C52, C55, C56 and C57) were found to tolerate the highest concentration of each metal tested. These isolates could be the potential ones to be used for heavy metal bioremediation. Further investigation is needed to explore their tolerance to other toxic heavy metals and to investigate the mechanism for metal resistance.

The exposure of microorganism to heavy metals results in the selection of bacterial strains which are also able to resist antibiotics. Many researchers reported isolation of heavy metal resistant organisms which showed multi drug resistance to antibiotics like Ampicillin, Tetracyclin, Ciprofloxacin, Gentamycin, Erythromycin, Streptomycin, Chloramphenicol and Nalidixic acid $^{11-13}$. Kannan and Lee ${ }^{13}$ isolated Bacillus cereus isolates from the sediments of Sunchon bay, South Korea which were resistant to various heavy metals like chromium, mercury, cobalt, manganese, zinc and several antibiotics like Ampicillin, Tetracycline, Kanamycin and Streptomycin. Similar to these reports, the isolates tested in the current study showed resistance to Ceftazidime, Ceftriaxone. Tetracycline, Ampicillin and Nalidixic acid in various degrees. In particular, the Bacillus isolates (isolate no C08, C10, C52, C55, C56 and C57), which were tolerant to the highest concentrations of lead, chromium, zinc and copper were also multi-drug resistant. This might be because genes encoding heavy metals are sometimes located on plasmids along with antibiotic resistance genes and therefore, it is likely that selective pressure by one such compound indirectly selects for the whole set of resistances. Alternatively bacteria might have unspecific mechanism of resistance common to different substances including heavy metals, biocides and antibiotics ${ }^{12,18}$. Further investigation of these heavy metal and antibiotic resistant Bacillus isolates at molecular level would provide insight into the plausible mechanism.

\section{Acknowledgement}

This work is funded by Ministry of Science and Technology, Govt. of the People's Republic of Bangladesh.

\section{Conclusion}

This study has isolated several Bacillus spp with tolerance to high concentration of toxic heavy metals lead, chromium, copper and Zinc as well as resistance to antibiotics from the Buriganga and Shitalakhya, two major rivers surrounding Dhaka. These bacterial isolates might have potential role in heavy metal bioremediation from polluted aquatic bodies. Further experiments are needed to elucidate the heavy metal bioremediation potential as well as mechanism of the isolates.

\section{References}

1. Islam, M.M., Akhter, M.K and M.S. Masud. 2006. Prediction of environmental flow to improve the water quaility in the river Buriganga. Proceedings of the $17^{\text {th }}$ AISTED International Conference on Modeling and Simulation, Montreal, QC, Canada.

2. Ahmad, M.K., Islam, S., Rahman, S., Haque, M.R. and M.M. Islam. 2010. Heavy Metals in Water, Sediment and Some Fishes of Buriganga River, Bangladesh. Int. J. Environ. Res., 4(2):321-332.

3. Environmental Quality Standards (EQS) for Bangladesh, Department of Environment, Government of Bangladesh. 1991

4. Baruthio, F.. 1992. Toxic effects of chromium and its compounds. Biol Trace Elem Res. 32:145-153.

5. Ilhan, S., Kilicrslan, S. and H. Odag. 2004. Removal of chromium, lead and copper ions from industrial waste waters by Staphylococcus saprophyticus. Turk Electron J Biotech. 2:50-57.

6. Murthy, S., Bali, G. and S.K. Sarangi. Biosorption of Lead by Bacillus cereus Isolated from Industrial Effluents. 2012. Brit Biotech J. 2(2): 73-84.

7. Rani, M.J., Hemambika, B., Hempriya, J. and V.R. Kannan. 2010. Comparative assessment of heavy metal removal by immobilized and dead cells: A biosorption approach. Afric J Env Sci Tech. 4(2): 77-83.

8. Mythili, K. and B. Karthikeyan. 2011. Bioremediation of Cr (VI) from Tannery effluent using Bacillus sppp and Staphylococcus spp. Int Multi Res J.1(6):38-41.

9. Ilias, M., Rafiqullah, I.M., Debnath, B.C., Mannan, K.S.B. and M.M. Hoq. 2011. Isolation and characterization of chromium (VI) -reducing bacteria from tannery effluents. Ind J Microbiol. 5(1):76-81.

10. Samanta, A., Bera, P., Khatun, M., Sinha, C., Pal, P., Lalee, A., and A. Manda. 2012. An investigation on heavy metal tolerance and antibiotic resistance properties of bacterial strain Bacillus spp. isolated from municipal waste. J. Microbiol. Biotech. 2 (1):178-189.

11. Selvi, T.A., Anjugam, E., Devi, R.A., Madhan, B., Kannppan, S. and 
B. Chandrasekran. 2012. Isolation and characterization of bacteria from tannery effluent treatment plant and their tolerance to heavy metals and antibiotics. Asian J Exp Biol Sci. 3(1):34-41.

12. Mgbemena, I.C., Nnokwe, J.C., Adjeroh, L.A. and N.N. Onyemekara. 2012. Resistance of bacteria isolated from Otamiri river to heavy metals and some selected antibiotics. Curr Res J Biol Sci. 4(5): 551-556.

13. Kannan, S.K. and K.J. Lee. 2008. Metal Tolerance and Antibiotic Resistance of Bacillus sppecies Isolated from Sunchon Bay Sediments, South Korea. 2008. Biotechnology. 7(1): 149-152.

14. Nath, S., Deb, B. and I. Sharma. 2012. Isolation and characterization of Cadmium and Lead resistant bacteria. Glob Adv Res J Microbiol. 1(11):194-198.
15. Bergey's Manual of Systematic Bacteriology. 2005. Edited by Garrity, G.M., Brenner, D.J., Krieg, N.R. and J.T. Staley. Williams and Wilkins, Baltimore, USA.

16. Barry, A.L. and C, Thornsberry. 1985. Susceptibility tests. Diffusion test procedures. In: Manual of Clinical Microbiology, $4^{\text {th }}$ edi. Lannette, E.H., Blows, A., Housler, W.J. and H.J. Shdomy. pp 978-979. American Society of Microbiology, Washington DC.

17. Bahig, A.E., Aly, E.A., Khaled, A.A. and K.A. Amel. 2008. Isolation, characterization and application of bacterial population from agricultural soil at Sohag Province, Egypt. Malay J Microbiol. 4(2): 42- 50.

18. Rajbanshi, A. 2008. Study on heavy metal resistant bacteria in Guheswori sewage treatment plant. Our nat. 6:52-57. 